TRAMES, 2008, 12(62/57), 2, 215-237

\title{
INNOVATION DIFFUSION AND ARCHITECTURE AND DYNAMICS OF LOCAL TERRITORIAL NETWORKS
}

\author{
Carmelo Cannarella, Valeria Piccioni \\ National Research Council of Italy (CNR), Institute of Chemical Methods (IMC)
}

\begin{abstract}
This paper aims to provide some guidelines for operators involved in local development related to the creation and management of territorial networks as critical tools to foster forms of efficient, effective and sustainable local development. Some models of local territorial networks' structure and dynamics are described on the basis of the contributions of the complex networks' theories. The definition of these models provides an important contributions in improving the success possibilities and impact capabilities of technological transfer initiatives and innovation diffusion action above all at local level on the basis of stable and long term systematic collaborations, not linked to isolated and extemporaneous initiatives.
\end{abstract}

DOI: $10.3176 /$ tr.2008.2.06

Keywords: territorial networks, local economies, knowledge flows, innovation management, rural development

\section{Introduction}

Local rural development is assumed to consist of complex transformation and adjustment processes based on the utilization and management of endogenous/ exogenous actual and potential human, economic and environmental resources occurring on a given territory. The combined action of these variables creates, often going beyond consolidated administrative borders, area-specific issues whose management requires a cross-area collective action (that can engage neighbouring territories also from different administrative regions) for the presence of cross-area problems and cross-area externalities (Reese 1997, Beer and Maude 2002, Beer et al. 2003). These variables can be encompassed in some analytical dimensions:

- economic factors - firms' structure and productivity, composition of the economic activities, firms' competitiveness degree at local, regional, national and international level, etc.;

- technological factors - technology penetration in local products and production processes and management, etc.; 
- geographical factors - physical and environmental conditions, geoeconomical advantages and disadvantages, etc.;

- infrastructural factors - infrastructural quality and quantity (roads, railways, transportation and storage facilities, energy, IT, etc.);

- cultural factors - educational levels, mentalities, local history, social relations, social exclusion and cohesion, etc.;

- institutional factors - quality and quantity of local administration and public services, presence or proximity to knowledge generators (universities, research centres, etc.) and extension agencies.

The dynamics and characteristics of these territorial patterns are often caused by some specificities of local development itself whose efficiency/inefficiency may be generated by adequacies/inadequacies in one or more of these dimensions: deficiencies in one of these dimensions usually imply appropriate compensation interventions in the other spheres as in the case of marginal areas with particularly adverse geophysical conditions whose development may be fostered for example through infrastructural and/or technological actions. Severe development crises may result from simultaneous collapses in all these dimensions. These inadequacies may operatively act as 'frictions' whose parallel actions may contribute to determine differences in sensibility and in reaction to innovation, change and development processes among neighbouring areas as well: in particular differences in performances in the institutional sphere may also explain why, in certain conditions, some static rural areas remain static even in the presence of a high potential innovation supply, consistent investments and subsidies, geophysical and geo-economic advantages or adequate infrastructure. These conditions highlight the critical role played by the institutional setting, and the related concepts of institutional strength/thickness, which may act as anchor and dynamo within development processes thus influencing the well-being of local communities through the production and provision of both private goods (which are expected to be obtained through the market) and public goods (health, security, education, environment, etc.). The importance of this role is also emphasized by the fact that public administrations have the primary responsibility in the provision of public goods and the eventual presence, quality and dimension of intentionally/ unintentionally executed forms of institutional inertia may be translated into the public agents' capability to avoid and correct development discrepancies linked to public goods, for example created by market failures. Local institutions also play a relevant role in stimulating collaborations and synergies among endogenous/ exogenous agents to attain common goals to solve development inadequacies: 'acting together' is in fact a critical precondition to support concrete and realistic development processes and to make all the investments conveyed into development actions and initiatives more effective and efficient. The construction of 'territorial networks' to link up local agents thus become an essential step to pass from competitive to cooperative conditions among local agents useful to make a territorial setting more robust against external negative perturbations, capable to properly exploit local resources and maintain 'in loco' the consequent richness 
and to strengthen and develop stable and long term systematic collaborations, not linked to isolated and extemporaneous initiatives. This condition concretely contributes to translate local collaborative pushes and forces into flexible structural processes useful to increase adaptation capabilities of local agents.

Territorial Networks are here defined as stable and long term formal/informal systematic relation collaborative webs among local agents operating within the same territory and sharing a common information and knowledge source on the basis of a more or less formal agreement.

This definition highlights the importance of territorial networks in primarily fostering forms of endogenous development thanks to the engagement of local agents and resources improving participatory approaches and direct involvement and overcoming the limits of exogenous initiatives falling 'from above'. They are also critical factors in enforcing and materializing the interrelations between innovation and processes of change whose role have been widely acknowledged and studied in literature (Antonelli 2003, Geels 2004, McAdam 2004, Ottosson and Björk 2004).

Nonetheless the solution of those difficulties in stimulating in practice at local level the development of these networks based on innovation and knowledge diffusion, in particular for those rural areas affected by stagnation and rigidity, still remains a problematic task. Even non marginal rural areas can show static conditions and resistances to innovation with direct consequences in terms of agricultural and rural economy decline, unemployment, natural resources degradation and erosion of quality of life for local communities. Many questions arise when a lack of cooperation among local agents is really at stake and territorial networks may provide the opportunity to encourage cooperation and make it concretely operative: how stimulate the development of these networks? How to concretely assemble them to effectively and efficiently make cooperation work? How to understand and manage their dynamics on the basis of their features, characteristics and architecture?

The aim of this study is to describe some operational approaches and tools developed for the creation of realistic collaboration networks at local level and to analyze their actual and potential performances directed at pursuing effective local development processes based on innovation and knowledge circulation. The present study is based on the adaptation and implementation of some critical contributions from complex network theories and some empirical observations and models implementation concretely carried out within the research activities of the project "Development Dynamics and Increases in Competitiveness of Rural Areas" (DICRA) resulting from an agreement between the Research Team on Development and Innovative Processes at the Institute of Chemical Methods (I.M.C.) of the National Research Council of Italy (C.N.R.) and the Municipality of Vitorchiano (a village with 4000 inhabitants in the province of Viterbo, about $100 \mathrm{~km}$ north of Rome in Central Italy). 


\section{Networks' architecture and dynamics: theoretical framework}

Many critical contributions for the concrete construction and management of local networks may derive from the theoretical research on complex systems in particular with regards to the systems' structure and adaptation phenomena. The adoption of these theories on complex systems is an essential step to the identification of some interpretative keys of many phenomena occurring in the creation, identification and development of operative cohesive relation networks among agents: many theoretical models can be adapted for the present study to describe for example the dynamics occurring in a rural area (considered as a "network of networks') under the influence of a large number of variables and local specific peculiarities which determine the real dynamic evolution of these networks (Lundstedt and Moss 1989, Holt 2002, Von Zedtwitz et al. 2003). This Section is not devoted to provide an exhaustive survey of the vast literature on these topics (Kickert 1997, Bollobàs 1998, Mantegna and Stanley 2000, Bollobàs 2001, Goh et al. 2002, Albert and Baràbasi 2002, Newman 2003) but rather to identify some focal issues specifically useful for the local networks' modeling and management when acting as engines capable of stimulating and boosting local development.

In their simplest form these systems can be defined as a collection of points or vertices $(N)$ which are connected by a variety of lines or edges. Vertices may represent different types of 'location' and in their applications vertices and edges can outline various types of business relations or infrastructural grids (i.e. transport networks or internet web) or human and social interactions.

a) Connection - Defining if the system is connected or disconnected is one of the first properties to look at (Fig 1) because the definition of an analytical model to describe and evaluate the connectivity status of the system is essential to understand if all the system's components are adequately involved in the processes thus determining the diffusion degree, through the edges, of eventual impacts and results among vertices (Barabàsi 2002).

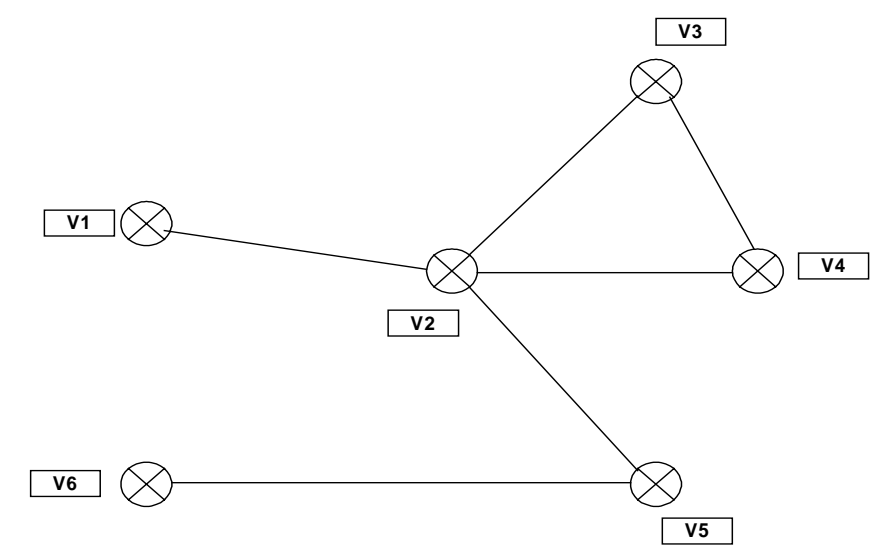

Figure 1. A connected 6 node, 6 edge network. 
b) Vertices' properties - The number $k$ of edges attached to a vertex (degree of a vertex) or the description of variety of degrees in the network summarized in the degree distribution $(K)$ represent other crucial interpretative keys. These properties are extremely important for the identification, description and development of dominant hubs within the network with a large number of paths passing through these hubs (vertex V2 in Fig 1). The presence of these hubs is related to the effect of 'power laws' translating, in some extent, a 'Pareto law' because many relation systems are not characterized by purely random interrelations but they show some 'preferential attachment' degree according to which new edges tend to attach preferentially to vertices with large degree $k$. Mathematical simulations show that power laws come from networks where there are hubs or vertices with more edges attached than the majority of vertices: in a large extent, the processes leading to the formation of stable connected networks require some type of 'preferential attachment' (Jeong et al. 2003, Vazquez 2003). The case of a totally dominant hub within a network can be expressed by a 'star network' (Fig 2) which describes the condition for which the entire system structure completely depends on a focal agent biasing an absolute influential degree for the network architecture. Examples of star networks are provided by those systems arranged completely around one agent or a local development process totally depending on one economic sector or a

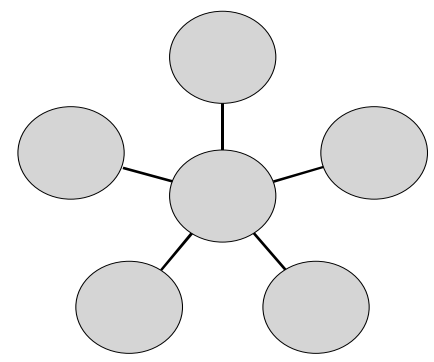

Figure 2. A star network. single firm.

c) Interaction strength - A system behaviour also relies on the strength of its interactions because the stronger the interactions, the better the agents are held together and the more energy it takes to disrupt the network assemblage. Interaction strength and the agents' rate of escape from the network thus express the inner system cohesion capability contributing to explain not only the quality of socio-economic interactions among networked agents but also the 'wealth' and the volatility of the system environment. In literature, the problem of the quantification of the links' strength has been widely discussed in theory (Marsden 1990, Albert et al. 2000, Dorogovtsev and Mendes 2000, Jain and Krishna 2001, Townley et al. 2003) but for development operators ${ }^{1}$ the evaluation of this parameter is a particularly difficult task because theoretical mathematical models not always fit in the real world. Some empirical observable evidences and symptoms may be organized and structured into three levels of link strength and network assemblage related to a rate $\lambda$ of existing link decay and a rate $\gamma$ of transmutation of strong links into weak connections throughout a scale ranging from 1 to 5 (Table 1).

1 For the aim of the present paper, the definition 'development operator' does not necessarily refer to a defined institutional or professional figure or role but rather to anyone directly or indirectly concerned with (local) development. 
Table 1. Strength of links in local networks

\begin{tabular}{|c|c|c|}
\hline Condition & Features & Parameters \\
\hline Integration & $\begin{array}{l}\text { Knowledge flows through hierarchical standards. } \\
\text { Agents utilize limited information and ideas from the } \\
\text { context. Communication is not an issue. Knowledge } \\
\text { flows within very limited spheres. Low coordination } \\
\text { and scarce agents' attitude in 'mixing' their } \\
\text { activities. }\end{array}$ & $\begin{array}{l}\text { High link decay and } \\
\text { transmutation degree } \\
(\lambda \text { and } \gamma=5 \text { or } 4)\end{array}$ \\
\hline Condensation & $\begin{array}{l}\text { Ideas are shared among groups of specialists. Agents } \\
\text { are involved in stable discussion groups. The net- } \\
\text { work shows an attitude to increase the number of } \\
\text { edges among agents. Medium coordination and } \\
\text { agents' magnitude in 'mixing' their activities. }\end{array}$ & $\begin{array}{l}\text { Medium link decay } \\
\text { and transmutation } \\
\text { degree } \\
(\lambda \text { and } \gamma=3)\end{array}$ \\
\hline Amalgamation & $\begin{array}{l}\text { The network holds melting pot mechanisms in which } \\
\text { agents work together showing a relevant coordina- } \\
\text { tion and significant magnitude in 'mixing' their } \\
\text { activities. Ideas, information and knowledge freely } \\
\text { flow within the network. All the agents (and the } \\
\text { subjects within the agents) contribute to generate and } \\
\text { improve knowledge. Knowledge flows transparently } \\
\text { and all the agents (and the subjects within the } \\
\text { agents) contribute to evaluate network's results and } \\
\text { impacts and optimize adjustment processes related } \\
\text { to innovative cycles. The network develops an } \\
\text { advanced communication structure. }\end{array}$ & $\begin{array}{l}\text { Low link decay and } \\
\text { transmutation degree } \\
(\lambda \text { and } \gamma=2 \text { or } 1)\end{array}$ \\
\hline
\end{tabular}

d) Network modelling - Many studies have aimed to analyze a network's dynamics with the description of their architecture. Some of these models are notably relevant for the evaluation of the modalities through which innovation propagates within social networks (Young 2003, 2007): for example the concept of Small Worlds (SW) is particularly pertinent when coping with innovation diffusion in small organizations or in rural areas because these networks are characterized by the shortest path connecting agents, a large clustering coefficients, the remarkable presence of hubs and power laws or the tendency to appear as relatively homogeneous networks. Furthermore the percolation theory can provide critical contributions in the description of the mechanisms of the emergence of connected clusters: percolation theory describes the development of transitions or dramatic changes in the qualitative behaviour of the network, triggered by infinitesimal modifications in the network parameters. These models highlight the interaction mechanisms among agents across a network essentially based on influencing forces which may modify the state of a neighbour agent which can drive to sets of affection of macroscopic sizes. Percolation theory can thus provide important indications about the mechanisms allowing or impeding 'global' diffusions and the fractions from which diffusion may (or may not) take place evidencing some 'critical values' for propagation. In particular some studies (Solomon et al. 2000) proposed the concept of 'Social Percolation' which con- 
siders society as a network through which a social phenomenon (information, values, opinions, beliefs, products, services, visions, behaviours) may, or may not, percolate. Other systems may assume the configuration of Scale Free (SF) networks for the tendency to follow power laws for large degree $k$ in distribution links (Albert and Barabàsi 2002). SF network models are essentially focused on the network dynamics and the processes that assembled the network rather than 'correct topological' features (path length, limited number of agents, etc.) as in the case of SW networks. Evolution is the central core of SF networks' analyses and topology becomes a sort of byproduct or a consequence of these evolution dynamics: rapid growth, due to the continuing addition of new vertices starting from a limited number of agents, time and preferential attachment (new agents are connected to vertices with high degree $k$ ) thus highly characterize SF networks.

\section{Networks' classification}

Local territorial networks can be considered as 'anthropological systems' in which vertices are expressed by agents (individuals, groups of individuals, firms, local institutions, research groups, etc.): being anthropological webs their links will indicate forms of relationship which cannot be just a simple function of the physical distance among agents (Wasserman and Faust 1994, Degenne 1999, Scott 2000, Watts et al. 2002, Kilduf 2003). Unlike infrastructural webs (transportations, energy grids, water or gas distribution systems) for these graphs vertices of a network have no position associated with them and the graph in Figure 1 thus has no structure other than its connections: the positions of its vertices in some real space are not an issue. These networks can be thus better visualized through some 'molecules' (Fig 3) also to emphasize some properties these local systems may eventually show: the distance of the edge in these molecules can sketch out, in a
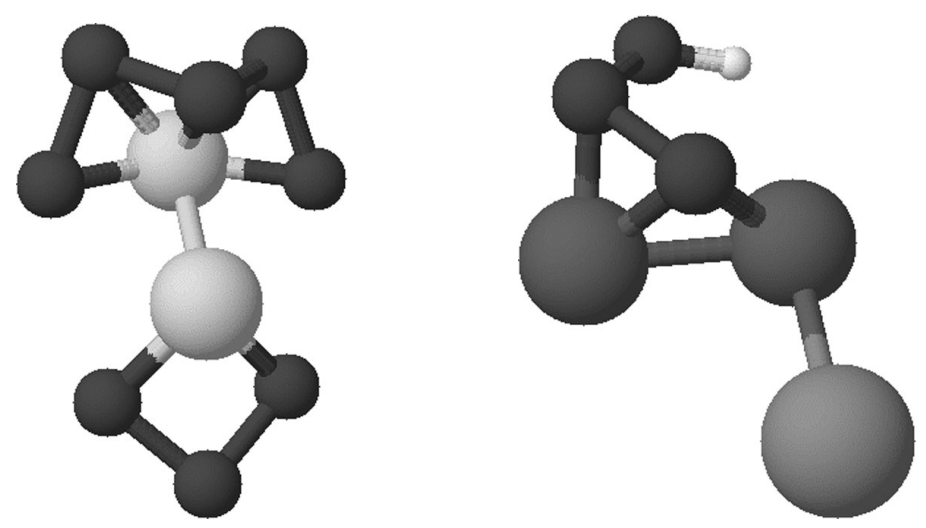

Figure 3. 'Molecular' representations of territorial networks 
some extent, integration, condensation or amalgamation phenomena, the dimension of each vertex may depict the agent's importance and role within the network, the colour may illustrate the agent's inclination to adopt or reject innovations, etc... In addition the molecules' shapes may outline the network's 'wealth' related to its optimal/sub-optimal behaviour according to the eventual insurgence of disturbing events caused by the networks' pathologies, causing fundamental modifications in the characteristics of the system structure and performance (Jensen and Lesser 2002, Cannarella and Piccioni 2006a).

Local networks may show a wide variety of features and characteristics whose classification can provide important contributions at operational level. These networks can be organized according to some parameters as described in Table 2.

Table 2. Classification of networks

\begin{tabular}{|c|c|c|c|c|}
\hline Parameter & Types & Features & Pro & Against \\
\hline \multirow[t]{2}{*}{ Nature } & $\begin{array}{l}\text { Formal } \\
\text { networks }\end{array}$ & $\begin{array}{l}\text { Networks created on the base } \\
\text { of explicit agreements among } \\
\text { agents which clearly define } \\
\text { an agent's roles, duties and } \\
\text { responsibilities, the network's } \\
\text { aims and scope, financial } \\
\text { aspects, etc. Many regional } \\
\text { rural development plans or } \\
\text { some EU scientific collabora- } \\
\text { tion schemes aim to create } \\
\text { such networks }\end{array}$ & Reliability & $\begin{array}{l}\text { Rather bureaucratic } \\
\text { networks. They have } \\
\text { to adapt to norms and } \\
\text { regulations and are } \\
\text { less flexible and malle- } \\
\text { able in case of chang- } \\
\text { ing conditions }\end{array}$ \\
\hline & $\begin{array}{l}\text { Informal } \\
\text { networks }\end{array}$ & $\begin{array}{l}\text { Networks resulting from } \\
\text { verbal or tacit agreements } \\
\text { among agents. They do not } \\
\text { have a well-structured } \\
\text { architecture and require a } \\
\text { tacit reiteration of the initial } \\
\text { unexpressed successful } \\
\text { agreement }\end{array}$ & $\begin{array}{l}\text { Less bureau- } \\
\text { cratic, rather } \\
\text { flexible net- } \\
\text { works; high } \\
\text { adjustment } \\
\text { degree in case } \\
\text { of changing } \\
\text { situations }\end{array}$ & $\begin{array}{l}\text { More vulnerable than } \\
\text { the formal ones } \\
\text { showing a discrete } \\
\text { volatility in case of } \\
\text { network's crisis }\end{array}$ \\
\hline \multirow[t]{2}{*}{$\begin{array}{l}\text { Configura- } \\
\text { tion }\end{array}$} & $\begin{array}{l}\text { Hierarchical } \\
\text { networks }\end{array}$ & $\begin{array}{l}\text { Presence of a dominant agent } \\
\text { difficult to be replaced for the } \\
\text { system existence, with an } \\
\text { already involved agent or new } \\
\text { network entrants }\end{array}$ & $\begin{array}{l}\text { High coordina- } \\
\text { tion and the } \\
\text { less influential } \\
\text { agents can be } \\
\text { easily replaced } \\
\text { with no effect } \\
\text { on the net- } \\
\text { work's fate }\end{array}$ & $\begin{array}{l}\text { The network creation } \\
\text { and development and } \\
\text { the achievement of the } \\
\text { related goals highly } \\
\text { rely on one influential } \\
\text { agent whose retirement } \\
\text { causes the network's } \\
\text { collapse (star network) }\end{array}$ \\
\hline & $\begin{array}{l}\text { Peer-to-peer } \\
\text { networks }\end{array}$ & $\begin{array}{l}\text { In these networks all the } \\
\text { involved agents are equally } \\
\text { important }\end{array}$ & $\begin{array}{l}\text { The network's } \\
\text { fate is not } \\
\text { linked to a } \\
\text { dominant agent } \\
\text { behaviour }\end{array}$ & $\begin{array}{l}\text { The network } \\
\text { performances and } \\
\text { existence can be put at } \\
\text { risk by the behaviour } \\
\text { of any agent }\end{array}$ \\
\hline
\end{tabular}


Another critical factor for the networks' classification is linked to the presence of some network generators: in certain circumstances the relation system acts as a skeleton requiring for its existence and survival, some additional parallel systems. Examples of this kind of networks are those originated by regional, national or EU funding in which these economic resources are the energy for the entire network and the funding organization plays the generator role: this parallel system, originated from the generator, does not always coincide with the relation network because, for example, the financial resources' flow does not reach all the agents involved in the network.

Other examples are provided by different parallel systems which can exist within the same network (economic, informative, coercion system, etc.) involving the network's agents at different level and degree. On the base of these considerations, local networks can show different perspectives, being identified as;

- Monodimensional - when these parallel systems coincide in the same network;

- Bidimensional - in the case of two not coinciding parallel systems within the same network;

- Tridimensional or Multidimensional - in the case of three or more not coinciding parallel systems within the same network.

\section{From competition to cooperation}

The capability of an area to act as a 'network of networks' (at economic, social and institutional level) operating within an environmental and cultural context becomes the key factor in supporting an effective development strategy to cope with stagnation and rigidities. It should be noted, however, that innovation diffusion, change or local networks' development cannot be imposed 'by law' and these processes are immersed not only in a socio-economic environment but also in a psychological one: in case of success programmes they may encourage for example cooperation, trust or spirit of initiative, but when failing, they may conversely generate an erosion of widespread responsibility, mistrust and social inertia. Conventional approaches to local development are essentially focused on technical and scientific issues while the dynamics of a given context tend to involve area specific processes encompassing not only technical elements but also organizational, cultural and psychological variables. The inclusion of these not quantifiable and intangible factors, enhancing quantifiable and tangible numerical elements, contributes in providing a realistic dynamic description of a socialeconomic environment, the modalities through which this context reacts to changes or propagates information and knowledge or the strategies adopted by local agents in adapting to modifications, etc.

The understanding of local dynamics should be therefore linked to a double faced analysis composed of two complementary and interacting problematic facets: an 'engineering' and a 'cultural' facet. The former problematic side is 
characterized by techniques, methods, technologies, etc. and by the corresponding organizational and social relations and it can be measured by conventional statistical and numerical approaches. The latter is rather linked to behaviours, actions and reactions, expectations etc. where the idea of positive/negative psychological results plays a critical role. Both dimensions contribute simultaneously to delineate the features of the relation systems among local agents (individuals, social groups, associations, firms, local institutions, etc.) on the basis of those specific peculiarities characterizing for example nature and mentalities of the agents involved, the territory where they operate, the role and action of local administrative institutions, local environmental resources and public goods and the modalities through which local agents interact with these resources, interrelations among agents and the output resulting from their interrelations, the expectation/ frustration balance, imitations and external contacts, trust/mistrust balances, etc.

A fundamental step for the creation of local networks is participation to prevent these initiatives from being injected in the area from above: many studies and empirical researches (Merrill-Sands and Collion 1994, Waage 1996, Hagmann, Chuma and Gundani 1997, Hagmann, Chuma and Murwira, 1997, Röling and de Jong 1998, Visser et. al. 1998, Norton et al. 1999, Abadi Ghadim et al. 2005) prove that an active participation (as opposed to summary consultation) of local agents has acquired increasing importance not only in problem diagnosis and in their needs' identification but also in organizing, testing and evaluating strategies, methods and practices useful to strengthen collaborative links, transmit innovation and research results and generate positive impacts in both public and private sectors.

The effectiveness and efficiency of an initiative directed to stimulate cooperation for the creation of networks based on innovation should be measured by its capability to promote, on the basis of circulation, negotiation and appropriation processes, innovative processes (Varga 1998, Feldman and Desrochers 2003, Lemon and Sahota 2004) capable of generating impacts or paths by which knowledge circulates, which can be translated for the agents into 'change' and substantial innovation, tangible benefits, interruption of routines and circular repetitions and activation of innovative cycles. Without participation, involvement, engagement and commitment any local development initiative will produce results 'on paper' but no impacts or negative impacts in the real world. Cooperation stimulation, as precondition for territorial networks' building is thus linked to a deep understanding of agents' profiles, needs and characteristics connected to a given context defined as already existing mentalities, behaviours, attitudes, approaches and practices in a consolidated environment: any innovation (and the related implementation and diffusion) hence doesn't grow in a 'ground zero' condition but it must be 'contextualized' (Cannarella and Piccioni 2003, Antoniou and Ansoff 2004). It means that a network building program should be flexible enough to be able to cope with specific local agents' peculiarities and needs (and not viceversa) thus acquiring context-specific features on the basis of some specificities: 
$>$ historical specificity;

$>$ local specificity;

$>$ relation specificity.

These local peculiarities should refer to the following 'network gears':

- individuation - capability of the involved agents to identify the elements at the base of the context, characteristics and relevance of the subjects involved, stimulating, at the same time, their own capability to recognize the presence and dynamics of territorial resources (human, environmental and economic capital) as specific peculiarities of the area;

- involvement - capability of the system to stimulate, support and improve the agents' inclination to be engaged in the system and to engage further agents;

- integration - capability of the system to stimulate and support agents to be functionally and effectively structured within the system;

- cooperation - capability of the system to stimulate and support agents to work together and concretely operate within the system.

The precondition for the proper functioning of these gears is linked to the management of some physiological gaps among agents generated by certain discrepancies (Intzell and Hilton 1999, Perez and Sànchez 2003, Izushi 2003, Fritsch 2003, Hearn et al. 2003, Brown and Michael 2003, Jamison and Hard 2003). An evaluation about the possibility to create collaborative local networks should be thus preceded by some considerations about these gaps and the modalities through which they can be managed according to some parameters (Relation Discrepancy - RD) on the basis of the following scheme:

a) discrepancy caused by the inner nature of the agents involved;

b) discrepancy in terms of distance: this aspect includes the problems caused by a physical distance among certain agents when too dispersed in the territory. If these agents are too distant, the possibility to stimulate positive and frequent relations, for the people involved, and to quickly meet each other are unavoidably eroded. Too long a distance implies also a limited knowledge of each other's characteristics and needs: proximity will facilitate the potential reciprocal comprehension about needs and problems useful to create partnership. This condition is also valid for scientific partnerships involving research groups for a technological transfer for which a psychological distance may occur, added to this physical distance: it derives by the fact that for example researchers and local agents often know little about each other. This causes a confrontation relation between 'adversaries' who consider many aspects of the other's world low profile issues, as they are not immediately evident and comprehensible. Frequently researchers tend to be not interested in many issues considered crucial by local agents and viceversa;

c) discrepancy in terms of time: local operators have their own 'time'; for example in many cases institutional activities and procedures last several years, whereas the needs for local agents can be generally short-term. This 
is the case of bureaucracy's time: this element is likely to play a critical role in the case, for example, of financing the projects, formal networks and other initiatives.

d) discrepancy in terms of interests and goals: local agents are different in nature having also different interests and goals. In addition to many development operators, objectives and results may be divorced from a global vision of the area where local agents operate: frequently the objective is too circumscribed, limited and partial, in particular when compared with a local agent's strategy;

e) discrepancy in terms of approach: local agents may often show completely different approaches when coping with problems and implications related to innovation;

f) discrepancy in terms of communication: local agents detain their own operational language and for example economic operators have their own sector idioms. Furthermore, administrative institutions tend to use two different languages. One is mainly based on juridical and legal terms and the other is tailored for specific intervention areas (agriculture, health, environment, scientific research, etc.). The result of this coexistence of languages is frequently translated into very complex documents which create severe communication problems between institutions and individuals and among different local entities;

g) discrepancy caused by different practices: local agents have their own practices and the lack of adequate knowledge of local agents' routines results in actions that, even if positive 'on paper', sometimes are operationally and concretely inappropriate;

h) discrepancy associated with financial problems: each local agent also shows different perspectives regarding financial aspects and issues.

These factors can be quantified and checked through some Divergence Intensity Charts (Figure 4) which can be used in a preliminary phase to quantify the consistence of the above cited discrepancies for the agents potentially involved in a future collaborative network and to dynamically monitor the evolution of the

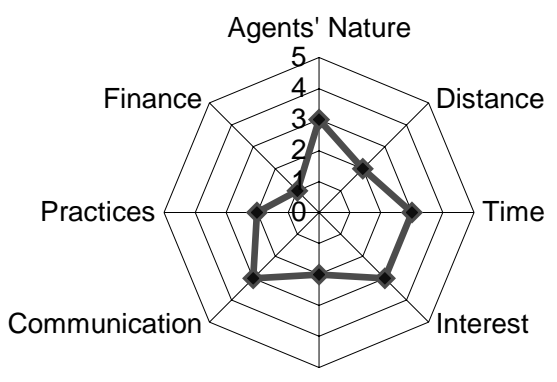

Approach

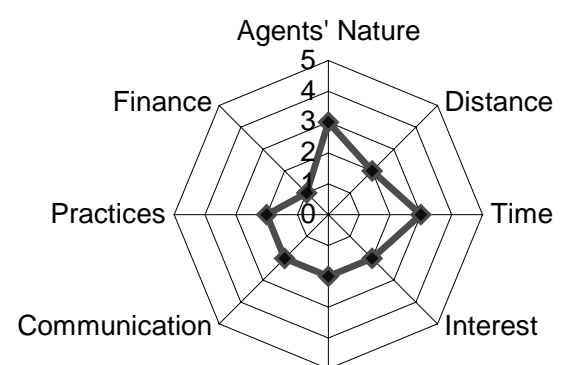

Approach

Figure 4. Divergence charts 
relation web once the network has been established: the wider the area, the stronger the pushes to competition and more limited the space for cooperation.

\section{Construction of local networks: problems and opportunities}

The construction of territorial networks among local agents implies the solution of eventual bundles of divergences and resistances to solve competitive pressures towards cooperation, the injection of the involved processes and the progressive passage from simpler integration levels to more advanced ones with the creation of complex knowledge networks. The first operative step thus involves the solution of ossified routines which often represent a precondition for the presence of resistances among local agents: routines are generally the simpler option, in economic, technological, management and psychological terms, when compared to unknown consequences of any kind of innovation and change. Resistances to innovation in network construction and development processes, at different scale (Table 3) are physiological components to cope with, sometimes however with positive correcting nature, requiring, for their realistic solution, highly convincing actions capable of stimulating imitation and impulses for next innovation clusters.

A clear vision about levels and types of resistances can provide relevant contributions in adopting more appropriate approaches to innovation diffusion and activation of knowledge flows through:

- Persuasion - modifying perceptions and opinions

- Negotiation - modifying priorities, identifying incentives and removing disincentives

- Attenuation - making resistances acceptable or not relevant

The main goal of these strategies is essentially to (re)gain trust as a precondition for any kind of development process based on cooperation. Trust cannot be triggered automatically because it must be cultivated and developed: of course these operations imply some costs and the deeper the mistrust the bigger the costs involved and the wider the failure margins. Gaining trust and maintaining the

Table 3. Classification of resistances

\begin{tabular}{|c|c|c|}
\hline Level & Scenario & Possible Strategies \\
\hline $\begin{array}{l}\text { Level } 1 \text { Opposition and } \\
\text { information }\end{array}$ & $\begin{array}{l}\text { People lack adequate information and } \\
\text { expertise about innovative actions }\end{array}$ & $\begin{array}{l}\text { Provide correct information. } \\
\text { Deliver basic training }\end{array}$ \\
\hline $\begin{array}{l}\text { Level } 2 \text { Opposition and } \\
\text { Utility }\end{array}$ & $\begin{array}{l}\text { People believe that innovation and } \\
\text { training are useless }\end{array}$ & $\begin{array}{l}\text { Deliver practical convincing } \\
\text { training based on successful } \\
\text { examples. }\end{array}$ \\
\hline $\begin{array}{l}\text { Level } 3 \text { Opposition and } \\
\text { Culture }\end{array}$ & $\begin{array}{l}\text { Consolidated practices prevail } \\
\text { systematically over innovation }\end{array}$ & $\begin{array}{l}\text { Cultivate innovation. Deliver } \\
\text { convincing training mainly } \\
\text { directed to young people to re- } \\
\text { create an innovation humus. }\end{array}$ \\
\hline
\end{tabular}


reached levels imply also time and multilevel commitment because mistrust propagates not only within the involved relations but it can also easily cast upon very far interrelations thanks to feedback chains. Many 'revenge' actions can be caused by mistrust stimulating anti-reactions capable of mobilizing consistent and uncontrolled energies: in brief, once trust is eroded, its regeneration will require very problematic ventures that are costly, time and resources consuming.

Operational approaches and methods adopted to solve resistance have to be critically examined in their potential to determine certain visions and opinions among local agents. In case of 'mature' contexts characterized by a widespread culture of innovation and high sensibility to changes a 'hammer' approach (Figure 5 left) is likely to be particularly efficient and effective because it produces immediate technical results capable of motivating innovators, promote high skilled human resources with the demolition of ossified practices and routines.

In other circumstances local agents may see the initiatives implemented to stimulate cooperation and create local networks as affairs for specialists, too focused on new technologies and too disruptive thus determining incentives for further even harder oppositions. In this case a more prudent approach is likely to be more suitable introducing slow and gradual changes with the involvement of large groups of human capital, improving the existing resources and the conventional know-how. This approach requires an identification of some pivotal individuals who show interest in innovation (potential innovators) to be directly engaged in the network's planning, design and implementation. These pivots, also

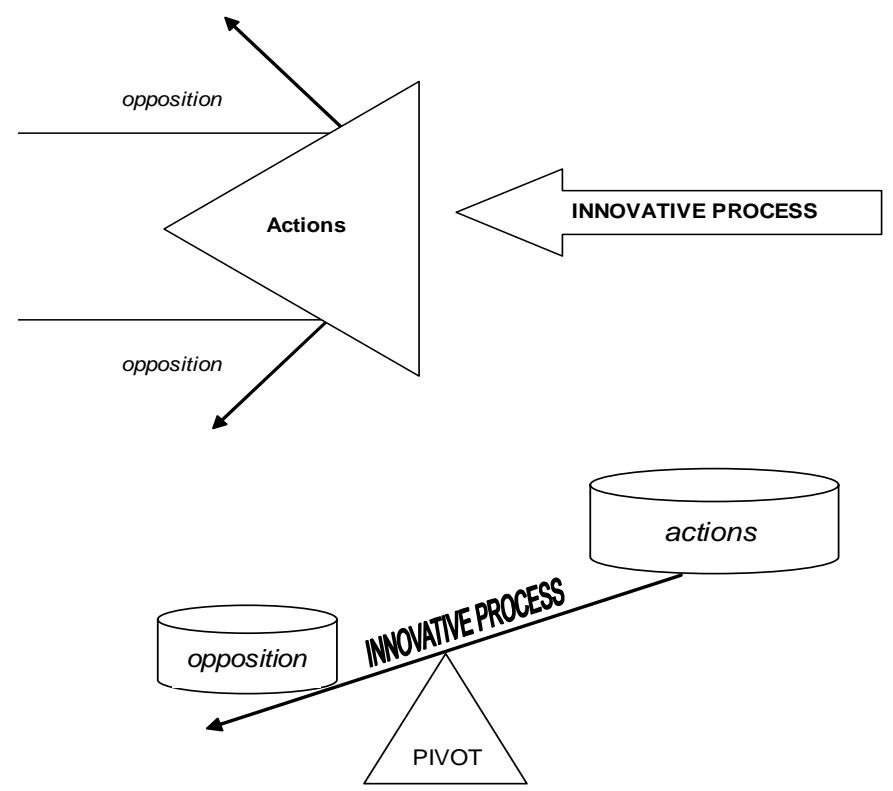

Figure 5. 'Hammer' (above) and pivotal (bottom) approaches in innovation introduction and local networks' construction 
stimulating positive word of mouth (PWOM) processes among less confident individuals (Figure 5 bottom) know better than the 'experts' the evolving problems of the local context and they also understand what motivates people and, fundamentally, have the power to make solutions work or fail. The main characteristics and features of these two approaches are summarised in Table 4.

Table 4. Pivot and hammer approaches: main features

\begin{tabular}{lccc}
\hline & Pivot & Hammer \\
\hline Investments required degree & Low & High \\
Efforts required degree & High & Low \\
Human resources involvement & High & Low \\
Priorities & Commitment and efforts & Results \\
Focus & Culture and mentality & Technology \\
\hline
\end{tabular}

The option between these approaches should result in a deep understanding of local agents' characteristics and needs and in a clear awareness about the inner features and progression course of the entire process. These networks have to be also self-sustaining entities based on innovation and knowledge circulation firstly overcoming the conventional limits of too bureaucratic programmes or technological transfer schemes (Burt, 1987) which are usually based on the clear distinction between two operational sides: givers (institutions, research centres, development or extensions agencies, etc.) and beneficiaries (i.e. enterprises, farms, individuals, associations, etc.). This distinction derives from an idea of local development based on pouring investments or doses of technical facts and messages towards ignorant/backward final users (Pretty and Chambers 1994). This vision results when development activities rain over a territory from a separate world taking place without any relevant involvement of local agents in any stage of the development cycle apart from some evaluations in applied technologies. This kind of approach, with an excessive emphasis in dissemination solutions to problems only generated by formal programs, with scarce or no consideration about the context's characteristics (Pretty 1995, Reardon and Barrett 2000) clearly tends to ignore some valuable local agents' experiences, traditional practices and insights contributing to generating gaps between these two worlds. For this reason, these schemes often provide unrealistic or uneconomic messages, which fail to take a holistic, user-centred perspective remarkably wasting a huge amount of public financial resources.

For the creation of an effective and efficient territorial network this distinction should be rather fluid and all the agents involved should have simultaneously the role of givers and beneficiaries: knowledge and information circulation being the essential core of these networks, increasing information, know-how and knowledge volume for the involved agents is not an issue but rather a mean to make the agents' information, expertise and knowledge (explicit/tacit) more productive. 
These networks should materialize knowledge and expertise for the activation of innovative cycles capable of breaking static and immobile conditions: putting these factors into concrete action implies also that overall know-how is tested meeting other agents' knowledge and expertise and, thanks to continuous adaptation processes, can be constantly transformed and potentially improved (Sugawara and Lesser 1998, Barabàsi et al. 2002, Herlocker et al. 2004, Clegg et al. 2005, Greve 2005). The entire process has to be supported by forms of continuing learning because good models and convincing examples are not enough when not incorporated in learning processes for the introduction and diffusion of knowledge and innovation and the solution of condition of inertia and resistance. Cooperation, integration, awareness and behaviour of the network's actors are highly influenced by learning which can be explained as learning-by-doing - experiences from production and design of goods (Arrow 1962, Garud 1997), learning-by-using (Rosenberg 1982) and learning by-interacting (Lundvall 1992). When local network creation and innovation circulation are connected to learning, these activities become more productive and functional for a human, social, cultural, economic and political growth also providing concrete contributions to capacity building processes conveying innovative know-how, enhance skills, awareness and expertise of the agents involved in the network. All this also contributes to facilitating commitment and enhancing the capacity of the agents involved to properly select options and choices and make well-informed decisions (Braun et al. 2000, Hall et al., 2001, Edwards and Eggers 2004).

The construction and development of a territorial network should clearly identify its components and critical elements as follows:

- context: the dimension within which the network and the related initiatives take place which can be identified by physical, geographical, economic, social, political, scientific, institutional elements;

- agents: including also 'interest focuses', encompassing the network's internal and external organizations and subjects;

- goals: the expected outcomes of the network;

- inputs: resources necessary to achieve the expected goals including also processing elements to translate goals into results and actions;

- actions: operational expressions of the network;

- results: the network' outcomes;

- products: concrete objects channelling and containing results;

- impacts: positive and negative modifications induced by the network's outcomes based on imitation, transfer and acquisition processes.

These parameters have to be coherent to some values and principles (Table 5) whose connection is described in the diagram of Figure 6.

A further critical step also involves the quantification of the levels of trust within a given target group to quantify local agents' confidence and attitudes. The first level includes the identification and quantification of the role of some trustkeys such as previous negative/positive experiences of similar initiatives and opinions and visions provided by others (Positive Word of Mouth - PWOM/ 
Table 5. Values and principles in the construction of networks

\begin{tabular}{l|l}
\hline \multicolumn{1}{c}{ Criteria } & \\
\hline Relevance & $\begin{array}{l}\text { Degree of accuracy in the identification of those elements on the basis of } \\
\text { the context, the characteristics of the agents involved, goals and } \\
\text { resources } \\
\text { Value of inputs, results and impacts. It also defines the agents' potential } \\
\text { in generating more and better results with the same inputs' quality and } \\
\text { Euantity }\end{array}$ \\
It defines how coherent goals and results are. It defines the actions' \\
capability to generate results \\
The modification degree, caused by the impacts, from the starting point. \\
Innovation & $\begin{array}{l}\text { It indicates the progression difference between 'before' and 'after' } \\
\text { The actions adopted are not isolated artificially events but it is possible to } \\
\text { register a great number of internal and external relations, complementary } \\
\text { actions, duplications, etc. } \\
\text { They define the extent according to which results and impacts generate } \\
\text { effective improvements (progress) compared to the starting conditions }\end{array}$ \\
Benefits & $\begin{array}{l}\text { It describes the accuracy degree according to which actions are adopted. } \\
\text { It also expresses the extent to which benefits generated by results and } \\
\text { impacts are distributed between agents }\end{array}$ \\
It describes how incisive impacts are. It expresses the difference between \\
(economic and non-economic) costs and benefits
\end{tabular}

Negative Word of Mouth - NWOM). The second level implicates the role of reputation also as first source of information useful to establish the degree according to which similar future options will be made (erosion/consolidation of reputation). Three types of trust can be identified:

$\square$ personal trust - deriving from direct knowledge of a specific person in the organization based on individual reputation and informal norms;

collective trust - deriving from direct knowledge of a group of individuals in the organization based on staff reputation and shared conventions;

$\square$ institutional trust - deriving from direct/indirect knowledge of the organization considered as an anonymous source of information based on definite norms, regulations, roles and procedures.

These forms of trust operate within three interrelated problematic dimensions:

$\square$ macro-level - the global context composed of political, juridical, legal, economic, social and cultural elements;

$\square$ intermediate level - groups and associations, trade unions, etc.;

$\square$ micro-level - personal behaviour and values

The third level involves the quantification of a perceived trust degree in the area which could be identified as a 'low trust level context' when agents perceive for example a sense of restriction, a sense of 'partiality', problems of politicization of public affairs, lack of neutrality by public organizations due to the development of privileged contacts, poor management of public goods: on the contrary, a 'high trust level context' should be considered an opposite environment. 


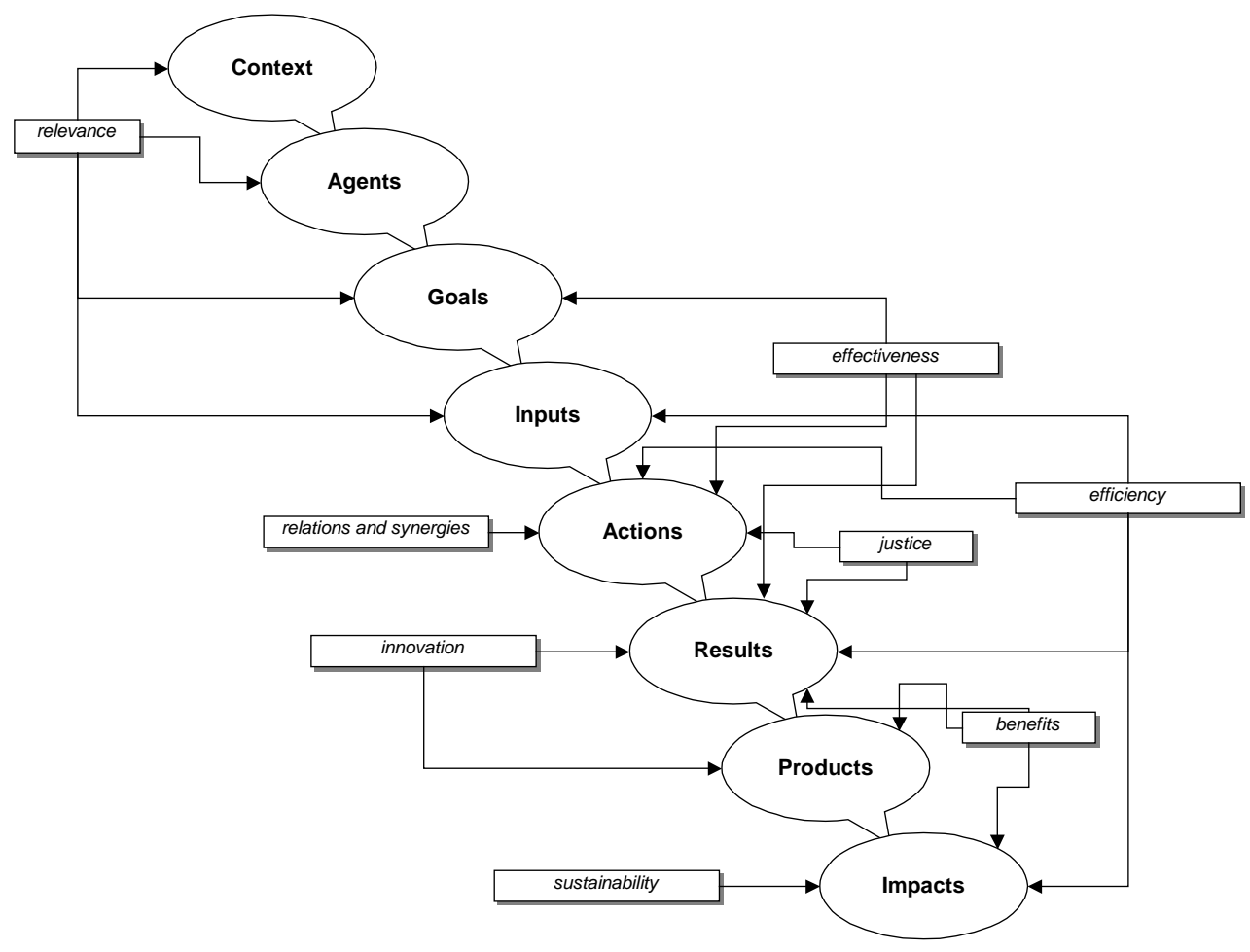

Figure 6. Network articulation, components and principles

\section{Conclusions}

Empirical experiences (Cannarella and Piccioni 2003) often highlight that some initiatives, regardless of their complexity or quality, have more impact than others due essentially to substantial differences in 'relation quality and capability' among agents determining the potential possibilities of success of each single initiative: similarly the impact of a local network is likely to be highly influenced by the dynamics occurring in the 'human factor'. In case of positive relations even simple initiatives may be capable of producing deep impacts on dramatically modifying methods, practices, techniques and above all mentalities: on the contrary, even in case of highly valid actions, scarce, cold or no relations among agents may produce only a very limited impact on a given context. The creation of these linkages is not however an easy task depending on the dialogue capabilities and on the will to establish synergies among subjects founded on reciprocal trust. Even in this case, collaborative actions must be convincing: the more trust is enhanced, the easier it is to engage dialogues, the more likely synergies will be achieved. These dialogues and synergies should always take into consideration the different agents' nature and visions. A too rigid demarcation among network agents and the tendency to treat innovation, knowledge management and their implication as 
purely technical issues to be solved by technical arguments can result in very restricted visions and limited impacts A better understanding of the social, economic, institutional and organizational linkages and tensions operating within the area should be transmitted and injected directly into the network (Scott 2003). Involving local agents in the network planning and design could be seen as trouble in the eyes of development operators, since it implies risks and complications: yet excluding local agents from the process may not alter the formal course of the programmes but it unavoidably undermines their substantial effectiveness. The lack of agents' involvement severely reduces the impact of the initiatives and actions adopted in the system and erodes the possibility for future activities. Empirical observations (Cannarella and Piccioni 2006b) also highlighted that, after a considerable effort to increase participation, conventional mode of 'top-down' recommendations, with scarce consideration and awareness of local agents' real problems and perceptions did not produce any significant result, frequently failed to generate any impact and, on the contrary, contributed to stimulate NWOM (Starbird 2003).

Development failures or scarce or no impacts resulting from development programmes can also be the outcome of the lack of collaborative networks among local agents or sub-optimal performances of the existing ones. Dissatisfaction and mistrust open concrete and critical questions about the validity of conventional approaches to (re)build such networks: the opportunity to adopt a more participatory approach for creating more robust links among local agents and to individuate paths and strategies for stimulating positive knowledge flows within a relation network are essential steps in order to learn to 'work together' and to support future initiatives and nourish trust.

Local networks can provide useful contributions in solving those conditions which act as substrate for a contraposition-based environment such as individualism, or a condition in which an agent improves its own performance by adversely affecting the context for other agents by making greater use of the context's resources normally shared by all the network agents. These conditions can become the cause for the generation of a number of resistances and oppositions to development, innovation introduction and change very difficult to deal with: for this reason local network creation and development require nonacademic methodologies and participatory appraisal techniques stimulating group discussions, visualization of processes, joint problem diagnosis and problemsolving. (Hagmann et al. 1997). A more participatory approach may also positively influence local institutions to promote local human, economic, environmental and cultural resources, to improve the overall quality of life of local communities.

The creation and development of an efficient and effective territorial network, as a critical tool to lead local agents towards common benefits and advantages, are notably affected by the action of a large number of variables and factors and by those specific peculiarities which characterize the agents involved, their interrelations, the results obtained and the expectation/frustration balance on the 
basis of the gratification mechanisms: in particular gratification represents an essential stimulus also for further external contacts and imitations. Success/failure of these initiatives in fact does not exclusively rely on the availability of economic resources: of course, with poor investments devoted to this aim the local agents will regard these initiatives with a rather mild 'enthusiasm'. So far, so obvious. Yet these actions can partially contribute to improving economic efficiency at economic level if based only on impersonal, simplified and homogeneous processes and results without taking into proper consideration the presence and insurgence in individuals of competition or static models in mental attitudes and in behaviour. For this reason, a territorial network is likely to produce effective positive impacts when technical and human facets of the issue are simultaneously concerned. Frequently, much effort directed to promote local development can be ineffective if the involved agents are not gratified even when huge investments are potentially available. These might considerably assist to the erosion of the individuals' spirit of initiative and creativity, increasing at the same time frustrations and mistrust; investments are thus definitively wasted and negatively allocated and managed. In conclusion, we would like to emphasize the empirical nature of this study pointing to some operational guidelines for those concretely concerned with local development essentially made on the authors' practical experiences: any observation, comment and criticism on our results and opinions is thus welcome.

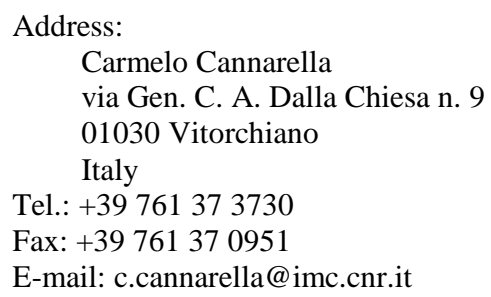

\section{References}

Abadi Ghadim, A. K., D. J. Pannell, and M. P. Burton (2005) "Risk, uncertainty, and learning in adoption of a crop innovation". Agricultural Economics 33, 1, 1-9.

Albert, R. and A.-L. Barabási (2002) "Statistical mechanics of complex networks". Reviews of Modern Physics 74, 1, 47-97.

Albert, R., H. Jeong, and A. L. Barabasi (2000) "Attack and error tolerance of complex networks" Nature 406, 378-382.

Antiniou, P. and I. Ansoff (2004) "Strategic management of technology". Technology Analysis \& Strategic Management 16, 2, 275-291.

Antonell,i C. (2003) The economics of innovation, new technologies and structural change. London: Routledge.

Arrow, K. (1962) “The economic implications of learning by doing". Review of Economic Studies $29,155-173$.

Barabasi, A.L. (2002) Linked: the new science of networks. Perseus. 
Barabasi, A.L., H. Jeong, E. Ravasz, Z. Neda, A. Schuberts, and T. Vicsek (2002) "Evolution of the social network of scientific collaborations". Physica A, 311, 590-614.

Beer, A. and A. Maude (2002) Local and regional economic development agencies in Australia. Report prepared for the Local Government Association of South Australia. Adelaide: School of Geography, Population and Environmental Management.

Beer, A., G. Haughton, and A. Maude (2003) Developing locally: an international comparison of local and regional economic development. Bristol, UK: The Policy Press.

Bollobàs, B. (1998) Modern graph theory. New York: Springer.

Bollobas, B. (2001) Random graphs. New York: Academic Press.

Braun, A. R., G. Thiele, and M. Fernández (2000) Farmer field schools and local Agricultural research committees: complementary platforms for integrated decision-making in sustainable agriculture. (Network Paper, 105.) London: Overseas Development Institute, Agricultural Research \& Extension.

Brown, N. And M. Michael (2003) "A sociology of expectations: retrospecting prospects and prospecting retrospects". Technology Analysis \& Strategic Management 15, 1, 3-18.

Burt, R. S. (1987) "Social contagion and innovation: cohesion versus structural equivalence". American Journal of Sociology 92, 1287-1335.

Cannarella, C. and V. Piccioni (2006a) "Dysfunctions and suboptimal behaviour in local rural networks". International Journal of Rural Management 2, 1, 29-56.

Cannarella, C. and V. Piccioni (2006b) "Training as innovation device". New Educational Review 8, $1,115-140$.

Cannarella, C. and V. Piccioni (2003) "Innovation transfer and rural SME's". Journal of Central European Agriculture 4, 4, 372-388.

Clegg, S. R., M. Kornberger, and C. Rhodes (2005) "Learning/becoming/organizing”. Organization $12,147-167$.

Degenne, A. (1999) Introducing social network. London: SAGE.

Dorogovtsev, S. N. and J. F. F. Mendes (2000) "Scaling behaviour of developing and decaying networks". Europhysics Letters 52, 33-39.

Edwards, W. M. And T. R. Eggers (2004) "Agricultural management e-school: extension education over the Internet". in American Journal of Agricultural Economics 86, 3, 778-781.

Feldman, M. and P. Desrochers (2003) "Research universities and local economic development: lessons from the history of the Johns Hopkins University". Industry and Innovation 10, 1, $5-24$.

Fritsch, M. (2003) “Does R\&D-cooperation behavior differ between regions?". Industry and Innovation $10,1,25-39$.

Garud, R. (1997) "On the distinction between know-how, know-why and know-what". Advances in strategic management $14,81-101$.

Geels, F. W. (2004) "From sectoral systems of innovation to socio-technical systems: insights about dynamics and change from sociology and institutional theory". Research Policy, 33, 6-7, 897-920.

Goh, K. I., E. Oh, H. Jeong, B. Kahng, and D. Kim (2002) "Classification of scale-free networks". Proceedings of the National Academy of Sciences of the United States of America 99, 1258312588.

Greve, H. R. (2005) "Interorganizational learning and heterogeneous social structure". Organization Studies 26, 1025-1047.

Hagmann, J., E. Chuma, and O. Gundani (1997) "From teaching to learning. Tools for learning about soil and water conservation". ILEIA Newsletter for Low External Input \& Sustainable Agriculture 13, 3, 26-27.

Hagmann, J., E. Chuma, and K. Murwira (1997) "Kuturaya: participatory research, innovation and extension". In Farmers' research in practice: lessons from the field. L. van Veldhuizen, A. Waters-Bayer, R. Ramirez, D. Johnson, and J. Thompson, eds. London; IT Publications.

Hall, A., N. Clark, S. Taylor, and V. R. Sulaiman (2001) Institutional learning through technical projects: horticulture technology $R \& D$ systems in India. (Agricultural Research \& Extension Network Paper, 111.) London, Overseas Development Institute. 
Hearn, G., D. Rooney D. T. Mandeville (2003) "Phenomenological turbulence and innovation in knowledge systems". Prometheus 21, 1, 231-245.

Herlocker, J. L., J. A. Konstan, L. G. Terveen, and J. T. Riedl (2004) "Evaluating collaborative filtering recommender systems". ACM Transactions on Information Systems 22, 1, 5-53.

Holt, K. (2002) Market oriented product innovation: a key to survival in the third millennium. Kluwer.

Intzell, A. and J. Hilton (1999) Technology transfer: from invention to innovation. Kluwer.

Izushi, H. (2003) "Impact of the length of relationships upon the use of research institutes by SMEs". Research Policy 32, 5, 771-788.

Jain, S., Krishna S. (2001) "A model for the emergence of cooperation, interdependence, and structure in evolving networks". Proceedings of the National Academy of Sciences of the United States of America 98, 543-547.

Jamison, A. and M. Hard (2003) "The story-lines of technological change: innovation, construction and appropriation”. Technology Analysis \& Strategic Management 15, 1, 81-91.

Jensen, D. and V. Lesser (2002) "Social pathologies of adaptive agents". In Safe Learning Agents: Paper from the 2002 AAAI Spring Symposium, 3-19. M. Barley and H. Guesgen, eds. Menlo Park, CA: AAAI Press.

Jeong, H., Z. Neda Z., and A. L. Barabasi (2003) "Measuring preferential attachment in evolving networks". Europhysics Letters 61, 567-572.

Kickert, W. J. M. (1997) Managing complex networks. London: SAGE.

Kilduf, M. (2003) Social networks and organizations. London: SAGE.

Lemon, M. and P. S. Sahota (2004) "Organizational culture as a knowledge repository from increased innovative capacity". Technovation 24, 6, 483-498.

Lundstedt, S. B. and T. H. Moss (1989) Managing innovation and change. Kluwer.

Lundvall, B.A. (1992) National systems of innovations: towards a theory of innovation and interactive learning. London: Printer Publisher.

Mantenga, R. and E. Stanley E. (2000) An introduction to econophysics. Cambridge: Cambridge University Press.

Marsden, P.V. (1990) "Network data and measurement". Annual Review of Sociology 16, 435-463.

McAdam, R. (2004) "Knowledge creation and idea generation: a critical quality perspective". Technovation 24, 9, 697-705.

Merrill-Sands, D. and M.-H. Collion (1994) "Farmers and researchers: the road to partnership". Agriculture \& Human Values 11, 26-37.

Newman, M. (2003) "The structure and function of complex networks". SIAM Review 45, 2, $167-$ 256.

Norton, G.A., D. Adamson, L. G. Aitken, L.J. Bilston, J. Foster, B. Franck, and J. S. Harper (1999) "Facilitating IPM: the role of participatory workshops". International Journal of Pest Management 45, 2, 85-90.

Ottosson, S. and E. Björk E. (2004) "Research on dynamic systems some considerations". Technovation $24,11,863-869$.

Perez, M.P. and A. M. Sànchez (2003) "The development of university spin-offs: early dynamics of technology transfer and networking". Technovation 23, 10, 823-831.

Pretty, J. and R. Chambers (1994) "Towards a learning paradigm: new professionalism and institutions for agriculture". In Beyond farmer first. Rural people's knowledge, agricultural research and extension practice, 182-202. I. Scoones and J. Thompson, eds. London Intermediate Technology Publications.

Pretty, J. N. (1995) "Regenerating agriculture. Policies and practice for sustainability and selfreliance". Earthscan (London) 157-160.

Reardon, T. and C. B. Barrett (2000) "Agroindustrialization, globalization, and international development. An overview of issues, patterns and determinants". Agricultural Economics 23, 195-205.

Reese, L. (1997) Local economic development policy: The United States and Canada. New York: Garland Publishing. 
Röling, N. and F. de Jong (1998) "Learning: shifting paradigms in education and extension studies". Journal of Agricultural Education \& Extension 5, 3, 143-161.

Rosenberg, N. (1982) Inside the black box: technology and economics. Cambridge: Cambridge University Press.

Scott, J. (2000) Social network analysis. London: SAGE.

Scott, J. T. (2003) "Absorptive capacity and the efficiency of research partnerships". Technology Analysis \& Strategic Management 15, 2, 247-253.

Solomon, S., G. Weisbuch, L. Arcangelis, N. de Jan, and D. Stauffer (2000) "Social percolation models". Physica A, 277, 239-247.

Starbird, S. A. (2003) "Graduate agribusiness management programs: too many and too cheap". Review of Agricultural Economics 25, 1, 271-276.

Sugawara, T. and V. Lesser (1998) "Learning to improve coordinated actions in cooperative distributed problem-solving environments". Machine Learning 33, 129-153.

Townley, B., D. Cooper, and L. Oakes (2003) "Performance measures and the rationalization of organizations". Organization Studies 24, 1045-1071.

Varga, A. (1998) University research and regional innovation. A spatial econometric analysis of academic technology transfers. Kluwer.

Vazquez, A. (2003) "Growing networks with local rules: preferential attachment, clustering hierarchy and degree correlations". Physics Review 67, 056104.

Visser, I., S. Cawley, and N. Röling (1998) "A co-learning approach to extension: soil nitrogenworkshops in Queensland, Australia”. Journal of Agricultural Education \& Extension 5, 3, 179-191.

Von Zedtwitz, M., G. Haour, T. Khalil, and L. A. Lefebvre, eds. (2003) Management of technology: growth through business innovation and entrepreneurship. Oxford: Pergamon Press.

Waage, J. (1996) “'Yes, but does it work in the field?' The challenge of technology transfer in biological control". Entomophaga 41, 315-332.

Wasserman, S. and K. Faust (1994) Social network analysis: methods and applications,. Cambridge: Cambridge University Press.

Watts, D. J., P. S. Dodds, and M. E. J. Newman (2002\}, "Identity and search in social networks". Science 296, 1302-1305.

Young, H. P. (2003) "The diffusion of innovations in social networks". In The economy as an evolving complex system. Vol. 3. L. E. Blume and S. N. Durlauf, eds. Oxford: Oxford University Press.

Young, H. P. (2007) Innovation diffusions in heterogeneous populations. (Discussion Paper Series, 303.) Department of Economics, University of Oxford. 